\title{
Electrochemical mineralization of norfloxacin using distinct boron-doped diamond anodes in a filter-press reactor, with investigations of toxicity and oxidation by-products
}

\author{
Douglas A.C. Coledama , José M. Aquino ${ }^{\mathrm{a}, *}$, Bianca F. Silva ${ }^{\mathrm{b}}$, Adilson José Silva ${ }^{\mathrm{c}}$, \\ Romeu C. Rocha-Filho ${ }^{\text {a,* }}$ \\ a Departamento de Química, Universidade Federal de São Carlos, C.P. 676, 13560-970 São Carlos, SP, Brazil \\ ${ }^{\mathrm{b}}$ Instituto de Química de Araraquara, Departamento de Química Analítica, Universidade Estadual Paulista, 14800-900 Araraquara, SP, Brazil \\ c Departamento de Engenharia Química, Universidade Federal de São Carlos, C.P. 676, 13560-970 São Carlos, SP, Brazil
}

\section{A R T I C L E I N F O}

\section{Article history:}

Received 1 June 2016

Received in revised form 29 July 2016

Accepted 2 August 2016

Available online 2 August 2016

\section{Keywords:}

Conductive diamond anode

fluoroquinolones

electrooxidation

toxicity assay to Escherichia coli

\begin{abstract}
A B S T R A C T
The contamination of water bodies by antibiotics is a cause of concern due to chronic toxic effects and the possible development of resistance to them by microorganisms, which can lead to serious health problems to humans. Thus, in this work, for the first time the degradation of norfloxacin $\left(100 \mathrm{mg} \mathrm{L}^{-1} \mathrm{NOR}\right.$ in $0.1 \mathrm{~mol} \mathrm{~L}^{-1} \mathrm{Na}_{2} \mathrm{SO}_{4}$ ) is carried out electrochemically, using a filter-press flow reactor with boron-doped diamond (BDD) anodes of distinct characteristics. The investigated variables (and their ranges) were solution $\mathrm{pH}\left(3,7,10\right.$, and without specific control), current density $\left(10,20\right.$, and $\left.30 \mathrm{~mA} \mathrm{~cm}^{-2}\right)$, temperature $\left(10,25\right.$, and $\left.40^{\circ} \mathrm{C}\right)$, and boron content $-\mathrm{sp}^{2} / \mathrm{sp}^{3}$ carbon ratio of the BDD anode $(100 \mathrm{ppm}-215,500 \mathrm{ppm}-$ 325 , and $2500 \mathrm{ppm}-284$ ). The NOR electrodegradation performance of the distinct anodes was assessed by monitoring the degradation by-products (aromatic compounds and carboxylic acids), NOR concentration and total organic carbon concentration of the electrolyzed solutions, as well as their toxicity to Escherichia coli (i.e. growth inhibition). For the complete removal of NOR, the best condition (not $\mathrm{pH}$ dependent) was attained at $10 \mathrm{~mA} \mathrm{~cm}^{-2}$ and $40^{\circ} \mathrm{C}$, when the system is under mass transfer limitations. Concerning NOR oxidation and mineralization rates, mineralization current efficiency, energy consumption, and degradation products, similar results (including the complete detoxification of the electrolyzed solution) were attained for all tested BDD anodes under mass or charge transfer controlled processes. Clearly, the oxidation power of the tested BDD anodes is not affected by the values of their boron content- $\mathrm{sp}^{2} / \mathrm{sp}^{3}$ carbon ratio.
\end{abstract}

(c) 2016 Elsevier Ltd. All rights reserved.

\section{INTRODUCTION}

The contamination of water bodies by synthetic organic compounds, such as dyes, plasticizers, personal care products, and antibiotics, has been the subject of many research papers mainly because fresh water is quickly becoming a scarce resource [1]. Among these synthetic compounds, antibiotics are a cause of concern due to chronic toxic effects and the possible development of resistance to them by microorganisms [2]. Antibiotics may enter the environment through excretion by humans and pet and farm animals, or through inadequate disposal of expired medicines. It is very unlikely that these organic compounds, usually at very low concentrations $\left(\mathrm{ng} \mathrm{L}^{-1}\right)$ [3], will be completely removed from contaminated urban wastewaters by conventional municipal treatment plants [4,5], mainly because antibiotics and other synthetic molecules have distinct physical chemical properties. Although little work has been done to assess the acute or chronic toxicity of synthetic compounds and their degradation products on organisms and plants and also their risk for humans [6], it is essential to eliminate these compounds from different wastewaters before disposing them in water bodies. Several processes may be used to remove antibiotics from wastewater, but ozonation,

\footnotetext{
* Corresponding authors.

E-mail addresses: jmaquino@ufscar.br (J.M. Aquino), romeu@ufscar.br (R.C. Rocha-Filho).
} 
Fenton/photo-Fenton and semiconductor photocatalysis have been the most tested processes $[7,8]$.

Indeed, as a consequence of the large compositional variability of contaminated wastewaters, there is not a single technology for their remediation [9]. Among the available methods for the degradation of organics contained in wastewater, electrochemical oxidation (or electrooxidation) might be a reasonable option considering its easy implementation, kinetic control, and high pollutant removal rates [9-15]. However, this technology is more adequately applied at low concentrations of dissolved organic compounds and without the presence of suspended solids; consequently, electrooxidation is usually recommended as a final treatment process. The main parameter that underlies electrooxidation methods is the anode material, which needs to be adequately chosen so that high oxidation rates and current efficiencies toward removal of organic compounds are attained [13-16]. These characteristics are better fulfilled when high oxidation power anodes are used [14], such as boron-doped diamond (BDD), tin dioxide, or lead dioxide; hydroxyl radicals $\left(\mathrm{HO}^{*}\right)$ electrogenerated on these anodes interact only weakly with the electrode surface and thus are highly reactive towards organics oxidation [16].

As pointed out by Kapalka et al. [16], BDD is an ideal anode material for the mineralization of organics; thus, it is being widely used nowadays in direct electrooxidation [10,17-20] and in combined treatment methods such as electro-Fenton [21-23], solar electro-Fenton [22], or sonoelectrochemical [24], as well as in the electrochemical detection [25-27], of distinct classes of organic substances. High mineralization rates and current efficiencies are attained with BDD anodes due to properties such as large electrochemical window and good corrosion stability [28], as well as the presence of quasi-free hydroxyl radicals on their surfaces [16,29]. Difficulties regarding the choice of adequate substrates for the BDD film growth and its stability during electrolysis [10], besides high prices, are still the main drawbacks of this anode material. Moreover, more work is needed on understanding the effect of boron content (and $\mathrm{sp}^{3} / \mathrm{sp}^{2}$ carbon ratio) on the mechanism of oxidation of organic compounds $[19,30,31]$ under specific hydrodynamic conditions.

Taking into account that the electrooxidation of fluoroquinolone antibiotics has been scarcely investigated [22,30,32], the aim of the present work is to compare the performances of BDD anodes of distinct characteristics in the electrooxidation of norfloxacin (NOR), a second-generation fluoroquinolone whose degradation by electrochemical methods has not been investigated, as far as we could ascertain. These electrooxidation performances in a filterpress flow reactor will be compared through the decays of the NOR concentration (assessed by high-performance liquid chromatography - HPLC) and total organic carbon (TOC) concentration, which give information on the efficiency of oxidation and mineralization (conversion to $\mathrm{CO}_{2}$ ), respectively. Furthermore, oxidation byproducts (aromatic compounds and carboxylic acids) will be investigated and compared for all tested BDD anodes, using liquid chromatography-tandem mass spectrometry (LC-MS/MS). Finally, the toxicity of the electrolyzed solution to Escherichia coli (E. coli) will be assessed along the electrolysis, whereas the results of the NOR electrooxidation process in the flow reactor will be compared to those of a theoretical model based on a process purely controlled by mass transport [33].

\section{Experimental}

\subsection{Chemicals}

All chemicals, including norfloxacin (99.9\% Vita Nova), $\mathrm{Na}_{2} \mathrm{SO}_{4}$ (a.r., Qhemis), $\mathrm{KH}_{2} \mathrm{PO}_{4}$ (a.r., Sigma Aldrich), $\mathrm{H}_{3} \mathrm{PO}_{4} \quad$ (85\%,
Mallinckrodt), $\mathrm{Na}_{2} \mathrm{~S}_{2} \mathrm{O}_{8}$ (a.r., Sigma Aldrich), methanol (HPLC grade, JT Baker), formic acid (HPLC grade, JT Baker), and other carboxylic acids (a.r., Sigma Aldrich), were used as received. Deionized water (Millipore Milli-Q system, resistivity $\geq 18.2 \mathrm{M} \Omega$ $\mathrm{cm}$ ) was used for the preparation of all solutions.

\subsection{BDD electrodes}

Boron-doped diamond (BDD) films (thickness of $2.9 \mu \mathrm{m}$ ), purchased from NeoCoat SA (Switzerland), were obtained by the hot filament chemical vapor deposition technique on monocrystalline Si p-doped substrates. Three different BDD anodes at varying specified boron content were used in the electrochemical experiments: 100 (215), 500 (325), and 2500 (284) ppm hereinafter, they will be referred to as $\mathrm{BDD}_{100}, \mathrm{BDD}_{500}$, and $\mathrm{BDD}_{2500}$, respectively; the values in parentheses refer to the $\mathrm{sp}^{3} / \mathrm{sp}^{2}$ carbon ratio determined by Raman spectroscopy, as provided by the manufacturer.

\subsection{Cyclic voltammetry measurements}

Cyclic voltammetry measurements of a naturally aerated $0.1 \mathrm{~mol} \mathrm{~L}^{-1} \mathrm{Na}_{2} \mathrm{SO}_{4}$ solution in the presence or absence of $100 \mathrm{mg} \mathrm{L}^{-1}$ NOR were performed in a conventional electrochemical cell at ambient temperature. The BDD anodes (exposed area: $0.49 \mathrm{~cm}^{2}$ ) were fixed through a Viton ${ }^{\circledR}$ O-ring to an acrylic holder that was directly immersed in the cell. $\mathrm{An} \mathrm{Ag} / \mathrm{AgCl}\left(3 \mathrm{~mol} \mathrm{~L}^{-1} \mathrm{KCl}\right)$ electrode and a platinum foil were used as reference and counter electrode, respectively. All measurements were carried out using a PGSTAT20 Autolab potentiostat/galvanostat controlled by the GPES software.

\subsection{Electrochemical degradation experiments}

The electrochemical degradation experiments were carried out in a one-compartment filter-press flow reactor containing a BDD anode and an AISI 304 stainless steel plate cathode (for a schematic representation of the flow cell used, see Fig. SC-1 in the supplementary content file). More information regarding the setup of the assembled electrochemical system is found elsewhere [34]. The exposed area of each anode was $3.54 \mathrm{~cm} \times 6.71 \mathrm{~cm}$. The investigated variables and their ranges in the electrooxidation of $100 \mathrm{mg} \mathrm{L}^{-1}\left(0.313 \mathrm{mmol} \mathrm{L}^{-1}\right)$ NOR solutions in $0.1 \mathrm{~mol} \mathrm{~L}^{-1} \mathrm{Na}_{2} \mathrm{SO}_{4}$ were: $\mathrm{pH}(3,7,10$, and without control), current density $(10,20$, and $\left.30 \mathrm{~mA} \mathrm{~cm}^{-2}\right)$, and temperature $\left(10,25\right.$, and $\left.40^{\circ} \mathrm{C}\right)$. A complete set of experiments was carried out using the $\mathrm{BDD}_{500}$ anode. Afterward, the remaining anodes were tested just for the optimized condition of those investigated variables. The solution $\mathrm{pH}$ was continuously monitored during each electrolysis and, if it were the case, kept constant at a desired value by additions of a concentrated solution of $\mathrm{H}_{2} \mathrm{SO}_{4}$ or $\mathrm{NaOH}$. The flow rate (flow velocity), electrolysis duration, and solution volume were fixed at $420 \mathrm{~L} \mathrm{~h}^{-1}\left(0.70 \mathrm{~m} \mathrm{~s}^{-1}\right)$, $300 \mathrm{~min}$, and $500 \mathrm{~mL}$, respectively. Before any degradation electrolysis, each anode was electrochemically pretreated in a $0.1 \mathrm{~mol} \mathrm{~L}^{-1} \mathrm{Na}_{2} \mathrm{SO}_{4}$ solution by applying $20 \mathrm{~mA} \mathrm{~cm}^{-2}$ for $15 \mathrm{~min}$ to eliminate any adsorbed organic compound.

\subsection{Analyses}

The evolution of the NOR concentration was monitored by HPLC using a core shell C-18 reversed phase as the stationary phase $\left(150 \mathrm{~mm} \times 4.6 \mathrm{~mm}, 5 \mu \mathrm{m}\right.$ particle size, from Phenomenex $\left.{ }^{\circledR}\right)$ and a mixture of $10 \mathrm{mmol} \mathrm{L}^{-1} \mathrm{KH}_{2} \mathrm{PO}_{4}$ at $\mathrm{pH} 3$ (eluent A) and methanol (eluent $\mathrm{B}$ ) as the mobile phase at $1 \mathrm{~mL} \mathrm{~min}^{-1}$ using a gradient elution protocol: from $10 \%$ to $90 \%$ of eluent $B$ in 10 min, and then 
back to $10 \%$ in $3 \mathrm{~min}$. The injection volume of the electrolyzed samples was $25 \mu \mathrm{L}$.

Analyses of oxidation by-products (intermediate compounds) were carried out every $1 \mathrm{~h}$ until $8 \mathrm{~h}$ of electrolysis. The electrolyzed samples of $2 \mathrm{~mL}$ were first frozen and then dried in a lyophilization system (CHRIST alpha 2-4 LD Plus) for $24 \mathrm{~h}$. Afterward, the samples were resuspended in $1 \mathrm{~mL}$ of methanol and filtered using a $0.22 \mu \mathrm{m}$ cartridge. Then, intermediate compounds formed during the NOR degradation were determined by LC-MS/MS using a 1200 Agilent Technologies LC chromatograph coupled to an AB SCIEX Instruments 3200 QTRAP mass spectrometer (linear ion trap quadrupole), operating in a positive mode, with a TurbolonSpray ${ }^{\mathbb{R}}$ probe. A special software, Lightsight ${ }^{\mathbb{R}} 2.3$ (Nominal Mass Metabolite ID Software, AB SCIEX), was used to investigate all possible intermediates. The application of the software was performed using the ionization and fragmentation parameters optimized for the initial compound; these parameters were obtained by direct infusion at a rate of $10 \mu \mathrm{L} \mathrm{min}^{-1}$ of the starting methanolic NOR solution diluted in acidic water, resulting in a methanol:water mixture as solvent $(1: 1, V / V, 0.1 \%$ formic acid). The MS conditions were: curtain gas at $20 \mathrm{psi}$, ion spray at $5200 \mathrm{~V}$, gases 1 and 2 at 50 psi, temperature of $600^{\circ} \mathrm{C}$, declustering potential of $41 \mathrm{~V}$, entrance potential of $8 \mathrm{~V}$, and with the interface heater turned on. Optimized selected reaction monitoring (SRM) and full-scan experiments were automatically performed by the LightSight ${ }^{\mathbb{R}} 2.3$ software. Different kinds of reactions were investigated, such as oxidation, hydroxylation, reduction, $\mathrm{C}-\mathrm{C}$ bond cleavage, and others. The LC analysis conditions for the MS measurements were those described earlier; however, the phosphate buffer used in the mobile phase was exchanged to an aqueous $0.1 \%(V / V)$ formic acid solution, whereas the injection volume was $20 \mu \mathrm{L}$. The solution samples collected at the electrolysis times of $0,1,2$, and $3 \mathrm{~h}$ were diluted to one third before the MS analyses.

Oxidation by-products in the form of short chain carboxylic acids were also determined throughout the electrolysis process by HPLC (UV detection at $210 \mathrm{~nm}$ ) using a Phenomenex ${ }^{\mathbb{R}}$ Rezek ROA$\mathrm{H}^{\mathrm{TM}}$ column as the stationary phase and $2.5 \mathrm{mmol} \mathrm{L}^{-1} \mathrm{H}_{2} \mathrm{SO}_{4}$ as the mobile phase at a flow rate of $0.5 \mathrm{~mL} \mathrm{~min}^{-1}$. Different carboxylic acids were identified by comparison of their retention times with those of previously analyzed standards. The injection volume and column temperature were maintained at $25 \mu \mathrm{L}$ and $23^{\circ} \mathrm{C}$, respectively.

The extent of mineralization (i.e. conversion to $\mathrm{CO}_{2}$ ) was monitored by measurements of the total organic carbon concentration ([TOC]) every $1 \mathrm{~h}$ using a GE Instruments Sievers Innovox TOC analyzer, with $\mathrm{H}_{3} \mathrm{PO}_{4}\left(6 \mathrm{~mol} \mathrm{~L}^{-1}\right)$ and $\mathrm{Na}_{2} \mathrm{~S}_{2} \mathrm{O}_{8}(30 \% \mathrm{~m} / \mathrm{m})$ as acidifying and oxidizing solutions, respectively. The values of [TOC] were obtained by subtraction of the measured values of inorganic and total carbon, in terms of generated $\mathrm{CO}_{2}$, obtained by interpolation from a previously determined calibration curve.

The toxicity test with $E$. coli was carried out with electrolyzed solution samples (after addition of few drops of a concentrated solution of $\mathrm{Na}_{2} \mathrm{~S}_{2} \mathrm{O}_{3}$ to eliminate any electrogenerated oxidant [35]) as well as with the initial solution. Tryptone, yeast extract, and $\mathrm{NaCl}$ (Lennox LB broth) were added to each sample to a final concentration of 10,5 , and $5 \mathrm{~g} \mathrm{~L}^{-1}$, respectively, and the obtained solutions were filter-sterilized. An overnight culture of $E$. coli K12 MG1655 was used to inoculate $15 \mathrm{~mL}$ Falcon $^{\mathrm{TM}}$ test tubes containing $3 \mathrm{~mL}$ samples, with $9 \times 10^{5} \mathrm{cfu} \mathrm{mL}^{-1}$ (cfu, colony forming units). Negative controls were prepared by inoculating three Falcon ${ }^{\mathrm{TM}}$ test tubes containing $3 \mathrm{~mL}$ of LB only. All test tubes (in triplicate for each analyzed electrolysis time) were incubated at $37{ }^{\circ} \mathrm{C}$ for $24 \mathrm{~h}$ at $200 \mathrm{rpm}$. After this period, E. coli growth was analyzed by measuring the absorbance of solutions at $600 \mathrm{~nm}$, and the toxicity of samples was assessed through the inhibition index
(I), calculated according to [36]:

$I=\left(\frac{A_{0}-A}{A_{0}}\right) 100$

where $A_{0}$ and $A$ are the absorbance in the absence (negative control samples) and presence (samples from all the investigated electrolysis times) of NOR, respectively.

The mineralization current efficiency $(M C E)$ was calculated as [37]:

$M C E=\frac{\Delta[\mathrm{TOC}]_{t} n F V}{4.32 \times 10^{7} \mathrm{mIt}} \times 100$

where $\Delta\left[\mathrm{TOC}_{t}\left(\mathrm{mg} \mathrm{L}^{-1}\right)\right.$ is the measured removal of [TOC] after a certain time $t(\mathrm{~h}), n$ is the number of exchanged electrons (assumed as 90 , considering that the total applied electric charge was consumed in the mineralization process), $F$ the Faraday constant $\left(96485 \mathrm{C} \mathrm{mol}^{-1}\right), 4.32 \times 10^{7}$ a conversion factor $\left(3600 \mathrm{~s} \mathrm{~h}^{-1} \times 12000\right.$ $\left.\mathrm{mg} \mathrm{mol}^{-1}\right), m$ the number of carbon atoms in the NOR molecule, and $I$ the applied electric current (A).

The extent of electrochemical combustion $(\phi)$ of the removed NOR [38] was calculated as the ratio between the percentages of [TOC] and [NOR] removal after each $1 \mathrm{~h}$ of electrolysis under the optimized conditions:

$\phi=\frac{\%[\mathrm{TOC}]_{\text {removed }}}{\%[\mathrm{NOR}]_{\text {removed }}}$

The value of $\phi$ gives an indication of the extent of conversion of the removed NOR molecules to $\mathrm{CO}_{2}$; thus, this parameter can assume values between 0 and 1, i.e. no combustion or total combustion with respect to the removed initial compound, respectively.

The energy consumption per unit mass $(w)$ for the electrooxidation process at a given reaction time $t(\mathrm{~h})$ was calculated according to [37]:

$w=\left(\frac{U I t}{\Delta[\mathrm{X}] V}\right)$

where $U$ is the cell voltage (V), $I$ the applied electric current (A), $\Delta[\mathrm{X}]$ the variation of the concentration of NOR or TOC $\left(\mathrm{mg} \mathrm{L}^{-1}\right)$, and $V$ the solution volume (L).

\section{Results and discussion}

\subsection{Cyclic voltammetry (CV) analysis}

Fig. 1 shows CV measurements (1st scan) using the BDD anodes in the absence and presence of NOR. As can be inferred from the figure, the $\mathrm{O}_{2}$ evolution reaction (OER) in the absence of the antibiotic becomes slightly more favored as the anode boron doping increases. It is also interesting to note that the oxidation peak at around $2 \mathrm{~V}$ also gradually increases with the boron doping level. This peak, which is probably related to the oxidation of $\mathrm{sp}^{2}$ carbon atoms in the surface of BDD [39], was also observed for a BDD (2500 ppm of boron) anode from another supplier [40]. In the presence of NOR, an initial oxidation peak at around $1.3 \mathrm{~V}$ and others at $1.7 \mathrm{~V}$ and $2.1 \mathrm{~V}$ show that this compound and its intermediates are promptly oxidized on the surface of all BDD anodes, without significant differences among them. However, when consecutive CV measurements are carried out (see Fig. SC-2 in the supplementary content file), the values of current densities gradually decrease (mainly at $2.5 \mathrm{~V}$ ), except for the $\mathrm{BDD}_{100}$ anode. This might indicate a surface blockage of active sites, which seems to be more prone to occur at the BDD anodes with higher boron doping levels, i.e., with more $\mathrm{sp}^{2}$ carbon atoms. 


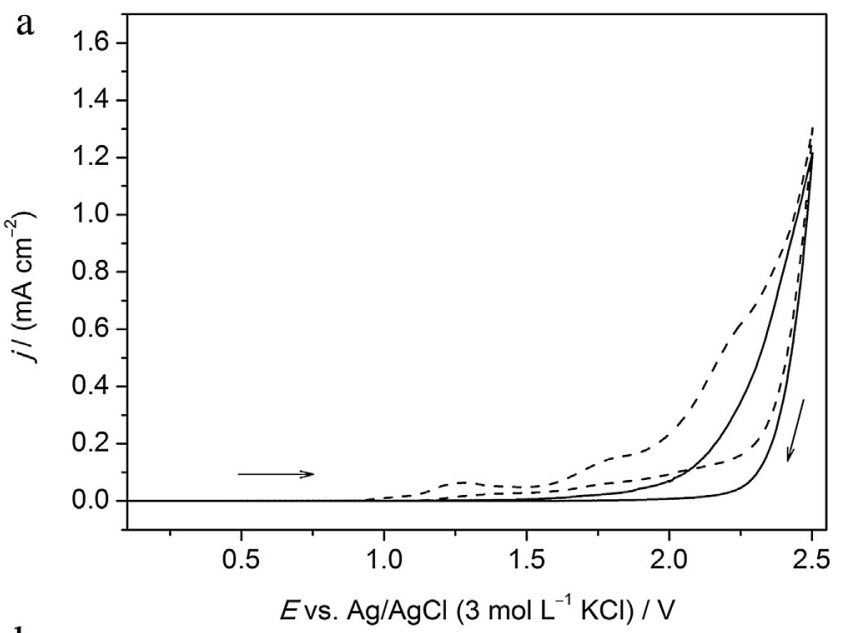

b

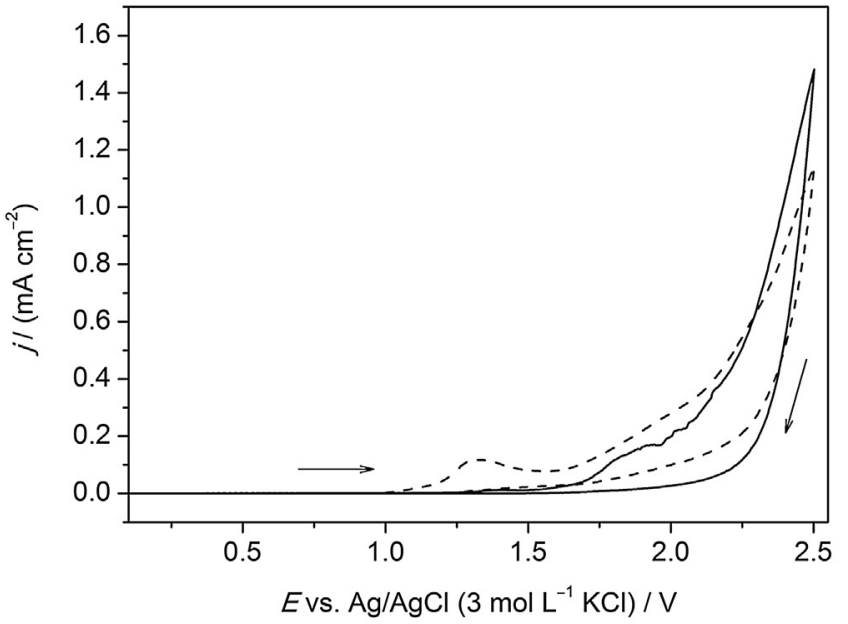

C

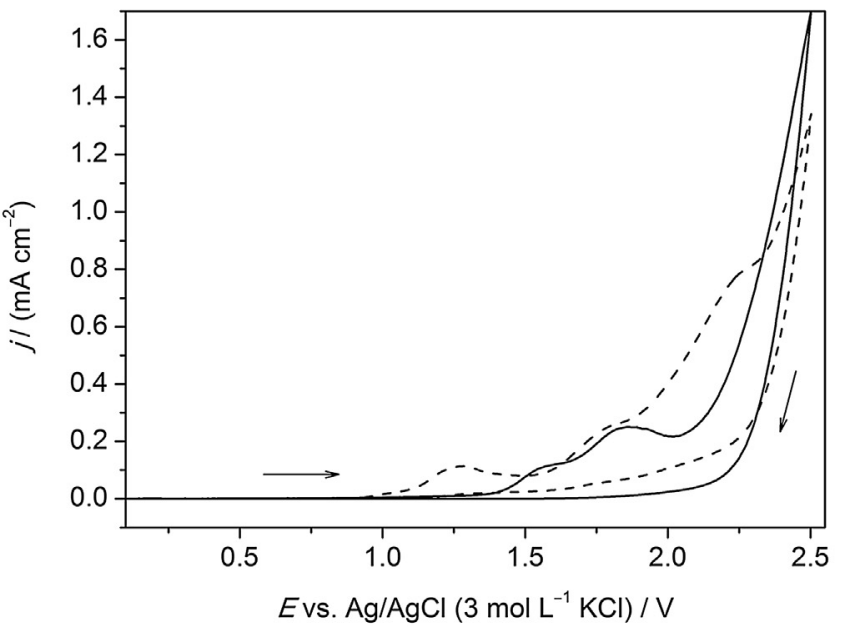

Fig. 1. Cyclic voltammetry (1st scan, $20 \mathrm{mV} \mathrm{s}^{-1}$ ) curve obtained using a) $\mathrm{BDD}_{100}$, b) $\mathrm{BDD}_{500}$ or c) $\mathrm{BDD}_{2500}$ anode in the absence (continuous line) and presence (dashed line) of $100 \mathrm{mg} \mathrm{L}^{-1} \mathrm{NOR}$ in $0.1 \mathrm{~mol} \mathrm{~L}^{-1} \mathrm{Na}_{2} \mathrm{SO}_{4}$, at $25^{\circ} \mathrm{C}$. The arrows indicate the scan direction.

\subsection{Effect of operational variables}

Fig. 2 shows the decay of the relative concentration of NOR $\left([\mathrm{NOR}]_{\mathrm{rel}}=[\mathrm{NOR}]_{t} /[\mathrm{NOR}]_{0}\right.$, where $[\mathrm{NOR}]_{t}$ and $[\mathrm{NOR}]_{0}$ are the $[\mathrm{NOR}]$ values at times $t$ and $t=0$ ) as a function of the applied charge per

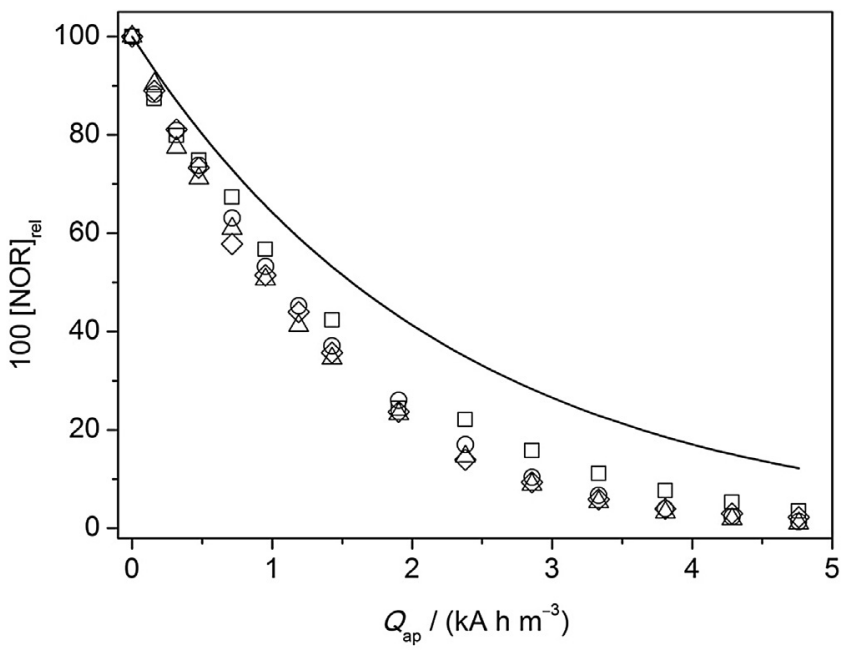

Fig. 2. Decay of the relative NOR concentration $\left(100[\mathrm{NOR}]_{\mathrm{rel}}\right)$ as a function of the applied charge per unit volume of electrolyzed solution $\left(Q_{a p}\right)$ using the $\mathrm{BDD}_{500}$ anode, for distinct solution $\mathrm{pH}$ values: $(\bigcirc) \mathrm{pH} 3,(\triangle) 7,(\diamond) 10$, and $(\square)$ no $\mathrm{pH}$ control; (-) theoretical line based on a purely mass transport controlled process. Electrolysis conditions: $20 \mathrm{~mA} \mathrm{~cm}^{-2}$ at $25^{\circ} \mathrm{C}$.

unit volume of electrolyzed solution ( $\left.Q_{\mathrm{ap}}\right)$, for electrolyses using the $\mathrm{BDD}_{500}$ anode at distinct solution $\mathrm{pH}$ values. It is interesting to observe that the solution pH does not significantly affect the NOR removal rates or extents (fitted using a pseudo-first order kinetic expression and whose $k_{1 \mathrm{st}}$ values remained around $1 \times 10^{-2} \mathrm{~min}^{-1}$, as can be seen in Table SC- 1 in the supplementary content file), despite its two distinct $\mathrm{p} K_{\mathrm{a}}$ values: 6.34 (carboxylic group) and 8.75 (nitrogen of the piperazine group). Similar results were obtained by Panizza and Cerisola [41] during the electrochemical degradation of the Methyl Red dye using a $\mathrm{BDD}_{3500}$ anode under conditions of mass transport control. This suggests that the ionic or molecular forms of the NOR molecule play no significant role on the oxidation mechanism. This also means that the electrooxidation process only depends on the transport of the organic species from the solution bulk to a region close to the anode, as indicated by the proximity of the theoretical exponential decay line of a purely mass transport (1st order) controlled process (Eq. (5)) and the obtained experimental values.

$\frac{[\mathrm{NOR}]_{t}}{[\mathrm{NOR}]_{0}}=\exp \left(-\frac{A k_{m} t}{V}\right)$

where $[N O R]_{t}$ and $[N O R]_{0}$ are the NOR concentrations at electrolysis times $t(\mathrm{~s})$ and $t=0, A$ is the exposed area $\left(\mathrm{m}^{2}\right)$ of the working electrode, $k_{\mathrm{m}}$ the mass transfer coefficient $\left(\mathrm{m} \mathrm{s}^{-1}\right)$, and $V$ the electrolyzed solution volume $\left(\mathrm{m}^{3}\right)$. The $k_{\mathrm{m}}$ value $\left(2.46 \times 10^{-5}\right.$ $\mathrm{m} \mathrm{s}^{-1}$ ) was calculated after obtaining the thickness of the limiting diffusion layer $\left(\delta_{\mathrm{D}}=2.29 \times 10^{-5} \mathrm{~m}\right)$ by a simple electrochemical assay based on the $\left[\mathrm{Fe}(\mathrm{CN})_{6}\right]^{4-} /\left[\mathrm{Fe}(\mathrm{CN})_{6}\right]^{3-}$ redox pair [42], and the NOR diffusion coefficient $\left(D_{\mathrm{NOR}}=5.65 \times 10^{-5} \mathrm{~m}^{2} \mathrm{~s}^{-1}\right)$ using a diaphragm cell. The observed deviation of the experimental values from the theoretical ones, which provide information on how fast the electrooxidation process can be carried out, is probably related to indirect oxidation processes (chemical oxidation) that occur in the solution bulk mediated by electrogenerated oxidants. As can be seen in Fig. SC-3 in the supplementary content file, the concentration of electrogenerated $\mathrm{H}_{2} \mathrm{O}_{2}$ increases with $Q_{a p}$, in the absence or presence of NOR, but at different rates. In both situations, up to $10 \mathrm{mg} \mathrm{L}^{-1}$ of $\mathrm{H}_{2} \mathrm{O}_{2}$ was detected by iodometric titration (performed according to standard practices [43]), without significant differences among the distinct BDD anodes. This 
behavior is different from the one reported by Fierro et al. [44], whose values of $\left[\mathrm{H}_{2} \mathrm{O}_{2}\right]$ varied for the distinct $\mathrm{BDD}$ anodes tested. As expected, the rate of production of this oxidant is higher in the absence of the antibiotic, as the electrogenerated hydroxyl radicals can more readily recombine over the anode surface to produce $\mathrm{H}_{2} \mathrm{O}_{2}$. These findings also suggest that chemical oxidation may also take place during the electrooxidation of NOR, leading to greater experimental pseudo-first order kinetic constants than the theoretical one.

Fig. 3 shows the decay of $[\mathrm{NOR}]_{\mathrm{rel}}$ as a function of $Q_{\mathrm{ap}}$ for distinct current density values investigated using the $\mathrm{BDD}_{500}$ anode. Clearly, low current density values lead to the highest removal rates of NOR, as the electrochemical system is under mass transfer limitations. At this point, it is possible to estimate the initial limiting current density $\left(j_{\lim }^{0}\right)$, using the following equation:

$j_{\lim }^{0}=n F k_{m}[\mathrm{NOR}]_{0}$

where $n$ is the number of electrons involved in the electrooxidation process (also assumed as equal to 90), $F$ the Faraday constant $\left(96485 \mathrm{C} \mathrm{mol}^{-1}\right)$, and $[\mathrm{NOR}]_{0}$ the initial concentration of NOR $\left(\mathrm{mol} \mathrm{m}^{-3}\right)$. The obtained value of $j_{\lim }^{0}$ was $7.9 \mathrm{mAcm}^{-2}$. Thus, any further increase in the value of the current density only leads to $\mathrm{O}_{2}$ evolution. It is important to highlight that there is the possibility to electrogenerate oxidants, as discussed above. This possibility could explain the increasingly greater difference between obtained and theoretical removal rates as the current density increases.

Fig. 4 shows the decay of [NOR $]_{\text {rel }}$ as a function of $Q_{a p}$ for distinct temperature values investigated using the $\mathrm{BDD}_{500}$ anode. As expected, the rate of NOR removal increases with temperature, which might be due to a gradual increase in the diffusion coefficient of NOR and its oxidation by-products with temperature. The possible increase of the oxidation power or concentration of the electrogenerated oxidants might also contribute to the removal of NOR. Moreover, when the experimental values of $[\mathrm{NOR}]_{\mathrm{rel}}$ at $25^{\circ} \mathrm{C}$ are compared to the theoretical ones, no agreement is observed, possibly due to additional chemical oxidation processes, e.g. those mediated by $\mathrm{H}_{2} \mathrm{O}_{2}$. Taking into account the above results, the remaining experiments were carried out at $40^{\circ} \mathrm{C}$, using $10 \mathrm{~mA} \mathrm{~cm}^{-2}$ and with no $\mathrm{pH}$ control.

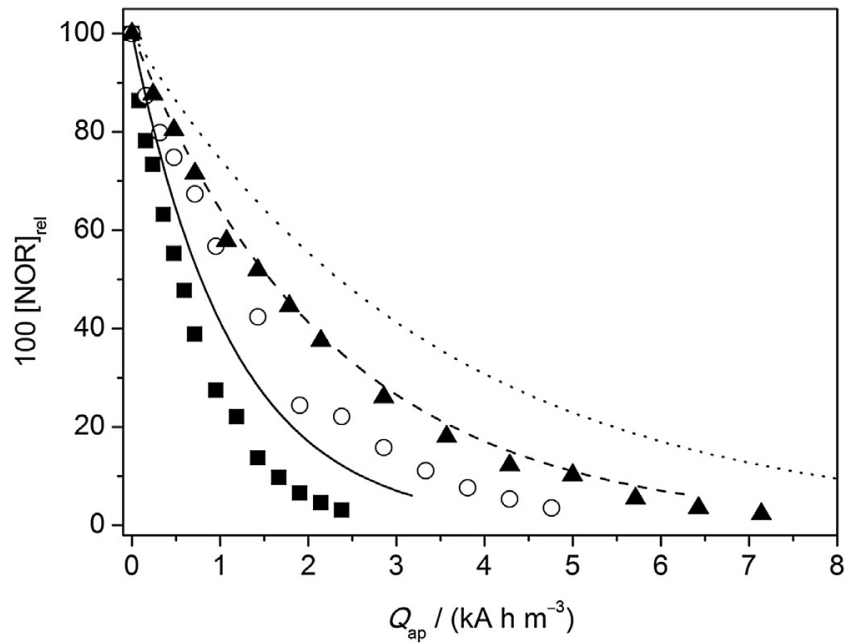

Fig. 3. Decay of the relative NOR concentration ( $\left.100[\mathrm{NOR}]_{\mathrm{rel}}\right)$ as a function of the applied charge per unit volume of electrolyzed solution $\left(Q_{\mathrm{ap}}\right)$ using the $\mathrm{BDD}_{500}$ anode at distinct current density values: $(\boldsymbol{\square}) 10$, ( $\bigcirc$ ) 20 , and $(\boldsymbol{A}) 30 \mathrm{~mA} \mathrm{~cm}^{-2}$; (-) theoretical line for $10 \mathrm{mAcm}^{-2},(--)$ theoretical line for $20 \mathrm{mAcm}^{-2}$, and $(\ldots)$ theoretical line for $30 \mathrm{~mA} \mathrm{~cm}^{-2}$. Electrolysis conditions: no $\mathrm{pH}$ control at $25^{\circ} \mathrm{C}$.

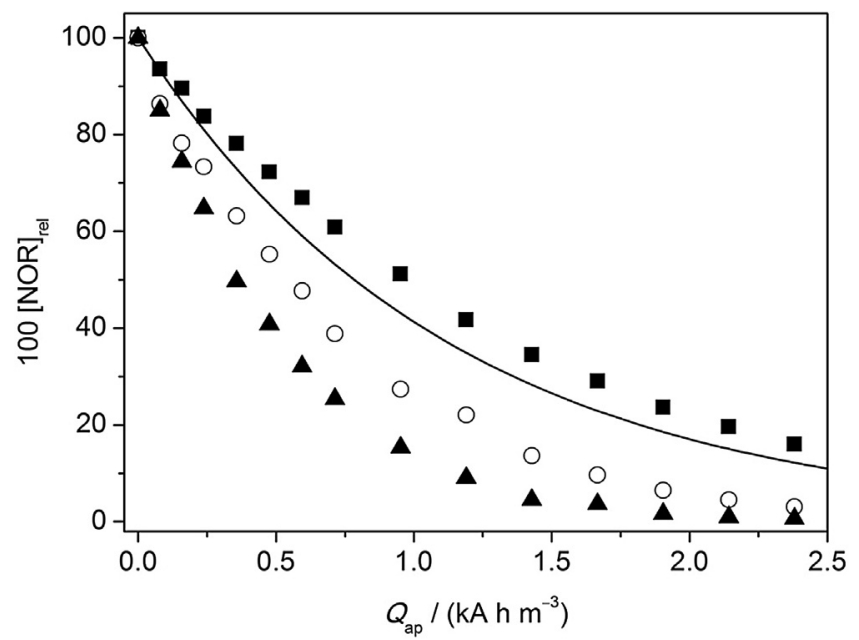

Fig. 4. Decay of the relative NOR concentration $\left(100[\mathrm{NOR}]_{\mathrm{rel}}\right)$ as a function of the applied charge per unit volume of electrolyzed solution $\left(Q_{\mathrm{ap}}\right)$ using the $\mathrm{BDD}_{500}$ anode at distinct temperatures values: $(\boldsymbol{\square}) 10$, (O) 25 , and $(\boldsymbol{\Delta}) 40^{\circ} \mathrm{C}$; (-) theoretical line based on a purely mass transport controlled process at $25^{\circ} \mathrm{C}$. Electrolysis conditions: $10 \mathrm{~mA} \mathrm{~cm}^{-2}$ and no $\mathrm{pH}$ control.

\subsection{Effect of the doping level of BDD anodes}

Fig. $5 \mathrm{a}$ and $\mathrm{b}$ show the decay of $[\mathrm{NOR}]_{\mathrm{rel}}$ and $[\mathrm{TOC}]$ as a function of $Q_{\mathrm{ap}}$, respectively, using BDD anodes at varying boron-doping levels. In the case of the [TOC] analyses (which give information on the conversion of NOR and its oxidation by-products to $\mathrm{CO}_{2}$ ), three electrolyses were carried out for each BDD anode. As can be observed in those figures, no significant differences in the levels of NOR or TOC removal were obtained for these anodes. In addition, the rates of NOR and TOC removal remained very close, with $k_{1 \mathrm{st}}$ values around $2 \times 10^{-2} \mathrm{~min}^{-1}$ and $6 \times 10^{-3} \mathrm{~min}^{-1}$, respectively, as can be seen in Table SC-2 in the supplementary content file. Those similar removal rates could be expected since the system is under mass transfer limitations, so every organic molecule that arrives at the electrode surface is promptly oxidized, i.e. there is enough availability of hydroxyl radicals for the organic molecule to be oxidized and mineralized, which is independent of the borondoping level. Fierro et al. [44] also observed no significant differences in the removal of the chemical oxygen demand

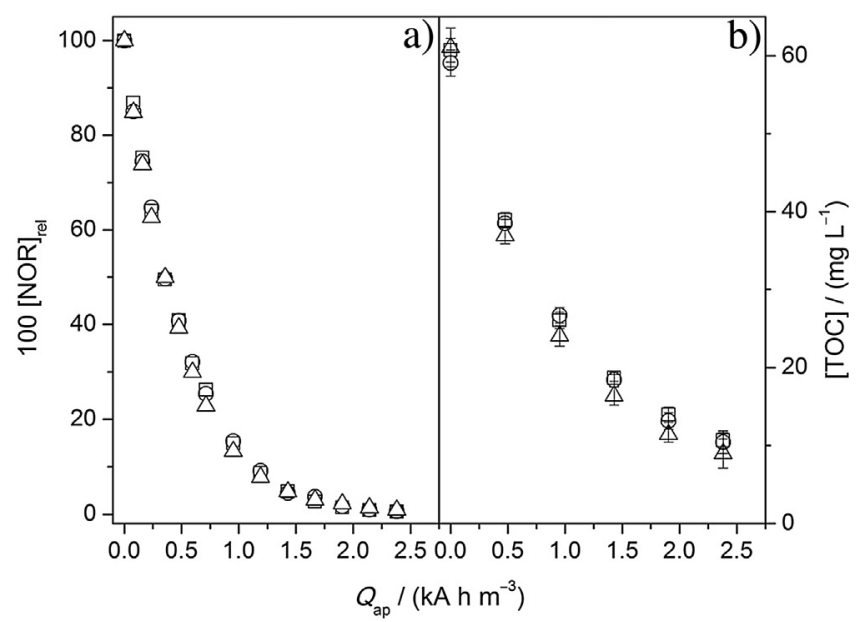

Fig. 5. Decay of the a) relative NOR concentration (100 $\left.[\mathrm{NOR}]_{\mathrm{rel}}\right)$ and b) absolute TOC concentration ([TOC]) as a function of the applied charge per unit volume of electrolyzed solution $\left(Q_{\mathrm{ap}}\right)$ for distinct BDD anodes at varying boron doping levels: ( $\square) 100 \mathrm{ppm}$, $(\bigcirc) 500 \mathrm{ppm}$, and $(\triangle) 2500 \mathrm{ppm}$. The [TOC] error bars refer to three repetitions. Electrolysis conditions: $10 \mathrm{~mA} \mathrm{~cm}^{-2}$ at $40^{\circ} \mathrm{C}$, and no $\mathrm{pH}$ control. 
(COD) of solutions containing formic acid when the electrolyses were carried out under mass transfer limitations using BDD anodes with distinct boron levels. In another work, de Araújo et al. [31] investigated the influence of the $\mathrm{sp}^{3} / \mathrm{sp}^{2}$ carbon ratio of $\mathrm{BDD}_{500}$ anodes on the removal of color, COD, and TOC of rhodamine $B(R h B)$ solutions. Despite the similar removal levels obtained for all tested anode materials, the ones with a higher diamond-carbon content (high $\mathrm{sp}^{3} / \mathrm{sp}^{2}$ carbon ratio) exhibited higher removal rates than the ones with a higher graphite-carbon content (low $\mathrm{sp}^{3} / \mathrm{sp}^{2}$ carbon ratio). This last material also favored the conversion of RhB to many intermediates, probably due to the adsorption of organic species on $\mathrm{sp}^{2}$ carbon atoms. Here it should be noted that, in this work, the $\mathrm{BDD}_{2500}$ anode showed an oxidation peak that is characteristic of $\mathrm{sp}^{2}$ carbon atoms (see Fig. 1); however, under mass transport conditions this did not lead to any significant differences in the oxidation or mineralization rates among the investigated BDD anodes (see Table SC-2 in the supplementary content file) - the same happened to the intermediate products, as discussed further below.

The effect of the BDD boron-doping level was also investigated for the removal of TOC under charge transfer control, i.e. using a small value of the applied electric current density $\left(j=1 \mathrm{mAcm}^{-2}\right)$. As can be observed in Fig. SC-4 in the supplementary content file, which shows the decay of $[\mathrm{TOC}]_{\mathrm{rel}}$ as a function of $Q_{\mathrm{ap}}$, no significant differences were observed in the TOC removal performance of all tested BDD anodes.

The values obtained for the extent of electrochemical combustion $(\phi)$ were very close for all tested BDD anodes and ranged from 0.6 , in the beginning of the electrolyses, to 0.8 after $5 \mathrm{~h}$, as can be seen in Table SC -3 in the supplementary content file. These results confirm once again the high mineralization power of BDD anodes, since practically all the removed NOR was converted to $\mathrm{CO}_{2}$ and $\mathrm{H}_{2} \mathrm{O}$ after $5 \mathrm{~h}$ of electrolysis.

Fig. $6 \mathrm{a}$ and $\mathrm{b}$ show the mineralization current efficiency $(M C E)$ and the energy consumption per unit mass of TOC removed $(w)$ as a function of [TOC], respectively, during electrolyses for the tested BDD anodes. As can be inferred from these figures, within the experimental errors, all BDD anodes exhibited similar behaviors for the MCE and $w$ values during the mineralization of NOR and its intermediates under mass transport controlled conditions. The initial high value of MCE gradually decreases with the

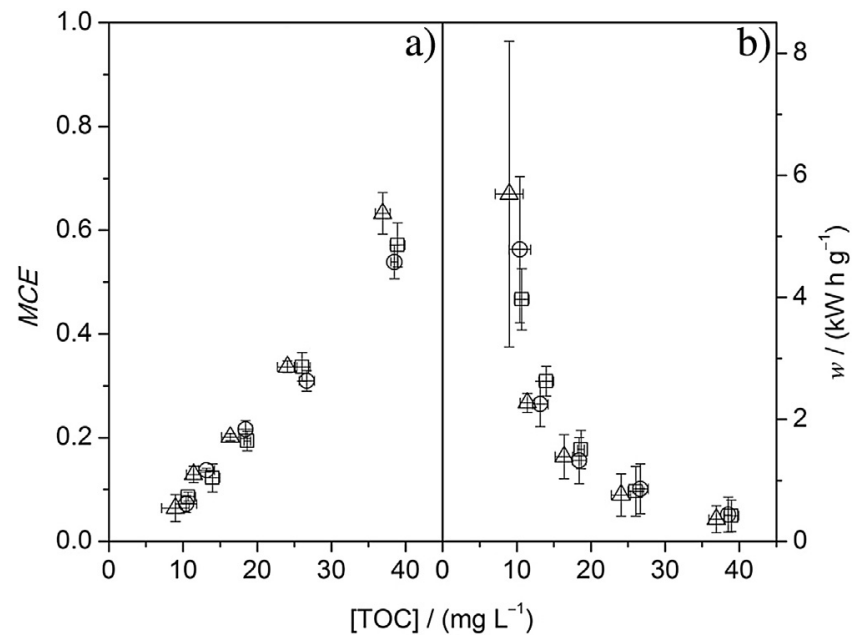

Fig. 6. a) Mineralization current efficiency $(M C E)$ and b) electric energy consumption per unit mass of TOC removed $(w)$ as a function of the absolute TOC concentration ([TOC]) during electrolyses using distinct BDD anodes at varying boron doping levels: $(\square) 100 \mathrm{ppm},(\bigcirc) 500 \mathrm{ppm}$, and $(\triangle) 2500 \mathrm{ppm}$. The error bars refer to three repetitions. Electrolysis conditions: $10 \mathrm{~mA} \mathrm{~cm}^{-2}$ at $40^{\circ} \mathrm{C}$, and no $\mathrm{pH}$ control. mineralization process, as the OER becomes the main electrode process in the final stages of the treatment. Consequently, an increase of the electric energy consumption was expected as the electrolysis progressed. Clearly, the characteristics of the BDD anodes had no influence on the mineralization process of NOR.

As can be seen in Table 1, the LC-MS/MS analyses showed that very few and the same intermediate compounds were generated during the electrooxidation of NOR using the distinct BDD anodes, except for the compound of $m / z 347$, which was detected only for the electrolysis using the $\mathrm{BDD}_{500}$ anode (for the proposed fragmentation route of the main detected intermediates, see Figs. SC -6 to SC -8 in the supplementary content file); somewhat similar results were reported by Souza et al. [45] for the degradation of the herbicide 2,4-D. This is an interesting result, which could be expected because the electrolysis was carried out under mass transfer limitations. Under these conditions, conversion to $\mathrm{CO}_{2}$ is high (as can be seen in Table SC-3 in the supplementary content file) and the generation of intermediates (considering their types and concentrations) is low, as previously highlighted by Comninellis and coworkers [16,29] and confirmed in this work by MS/MS analysis. Souza et al. $[46,47]$ also reported a small number of intermediate compounds during the electrooxidation of the dimethyl phthalate ester using a BDD anode in comparison to a medium oxidation power $\beta-\mathrm{PbO}_{2}$ anode. Clearly, the $\mathrm{HO}^{\bullet}$ concentration in the anodic reaction zone [48] is sufficient to promote the almost complete mineralization of NOR, independently of the characteristics of the BDD anode. The main detected intermediate compounds, whose absolute intensities were very low, resulted from hydroxylation reactions in the quinolone and piperazine rings of the parent compound; these intermediates were also detected when the degradation of NOR was carried out by other methods [49-53]. The chemical structure of the compound of $m / z 348$ was not confirmed by MS/MS analyses due to its low detected amount. It is important to highlight that other intermediates were generated; however, their concentrations were too low, close to the background signal.

The main carboxylic acids detected by HPLC for all tested BDD anodes were: butyric, glycolic, glyoxylic, oxalic, oxamic, propionic, and tartronic acid (see Fig. 7, for the electrolysis using the $\mathrm{BDD}_{500}$ anode; for the electrolyses using the other anodes, see Fig. SC-5 in the supplementary content file); these acids were formed by the opening of the quinolone and piperazine rings, with subsequent oxidation steps. Among these compounds, the ones that presented the highest concentrations were the oxalic, oxamic, and tartronic acids; moreover, only a very small amount of lowly oxidized carboxylic acids, such as butyric and propionic acid, was detected. The high concentration of oxalic acid, which is one of the last formed by-products before $\mathrm{CO}_{2}$ generation, as described by GarciaSegura and Brillas [54], is a further indication of the high oxidation power of BDD anodes. The fact that the same carboxylic acids were generated for all tested BDD anodes indicates that the characteristics of the distinct BDD anodes do not exert any influence on the type of short chain intermediate compounds generated during the electrooxidation of NOR under mass transport control.

Finally, Fig. 8 shows the evolution of [NOR] and the inhibition index $(I)$ as a function of electrolysis time using the $\mathrm{BDD}_{500}$ anode. It is interesting to observe how the initial process of NOR electrooxidation (first $2 \mathrm{~h}$, more than $80 \%$ [NOR] removal, basically through $\mathrm{HO}^{*}$ addition reactions) did not lead to the cessation of the antibiotics inhibition of the growth of $E$. coli because the fluoroquinolone structure was not broken. Then, after $2 \mathrm{~h}$ of electrolysis, the inhibition growth index $(I)$ is significantly decreased, most probably because of the breaking of the fluoroquinolone structure mediated by hydroxylation reactions on the surface of the BDD anode (mineralization process; see e.g. compound with $m / z$ ratio equal to 285 in Table 1 ), leading to non- 
Table 1

LC-MS/MS data for the intermediate compounds detected during the electrooxidation of norfloxacin using BDD anodes at varying boron-doping levels.

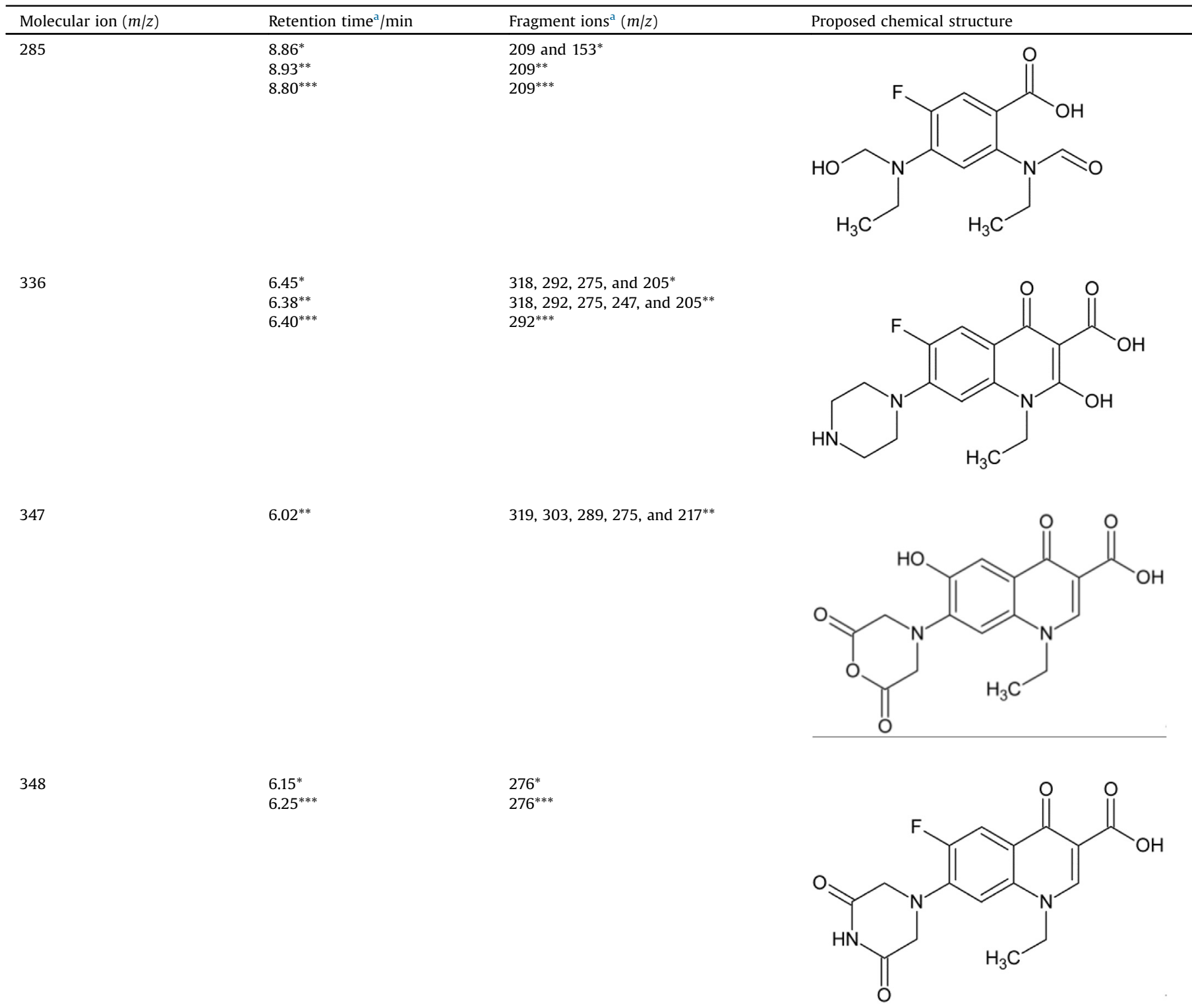

\footnotetext{
a Retention time and fragment ions of the intermediate compounds detected using a (*) $\mathrm{BDD}_{100},\left({ }^{* *}\right) \mathrm{BDD}_{500}$ or $\left({ }^{* * *}\right) \mathrm{BDD}_{2500}$ anode.
}

toxic by-products towards $E$. coli (including the detected carboxylic acids, see Fig. 7) and ceasing the inhibition of the bacteria. The notably decreased value of [NOR] may also be contributing to the significant decrease of $I$. In fact, another important aspect that agrees with the decreasing values of $I$ is the minimum inhibition concentration (MIC) of NOR towards E. coli, which is below $1 \mathrm{mg} \mathrm{L}^{-1}$ [55]. Clearly, during electrolysis this MIC value is only attained after $4 \mathrm{~h}$, when the inhibition index becomes almost null (see Fig. 8). These results are in agreement with the TOC removal and extent of electrochemical combustion data, as practically all the organic load ( 90\%) is removed after $5 \mathrm{~h}$ of electrolysis.

\subsection{Comparisons with electrooxidations of other fluoroquinolones}

As mentioned before, the electrooxidation of fluoroquinolone antibiotics has been scarcely investigated, mainly by Brillas and coworkers who also have used BDD anodes: enrofloxacin (ENRO)
[30,32] and ciprofloxacin [22]; just recently, Gong et al. [56] reported on the electrochemical degradation of levofloxacin (LEVO) using $\mathrm{RuO}_{2} / \mathrm{Ti}$ electrodes. All these studies were carried out in conventional two-electrode cells, with stirring. In the case of ENRO, the role of several characteristics (including $\mathrm{sp}^{3} / \mathrm{sp}^{2} \mathrm{C}$ ratio) of BDD films on their electrooxidation performance was investigated [30]; however, the investigated $\mathrm{sp}^{3} / \mathrm{sp}^{2} \mathrm{C}$ ratios were significantly lower $(\leq 105)$ than the ones of the BDD anodes used in the present work $(\geq 215)$, i.e. the former BDD films are richer in graphite-carbon. In fact, contrary to what we report hereinabove, Brillas and coworkers [30] found that the TOC removal performance of the BDD films significantly increased with the $\mathrm{sp}^{3} / \mathrm{sp}^{2} \mathrm{C}$ ratio for the electrooxidation of ENRO, which was explained as due to consequent increased electrogeneration of oxidants (increased oxidation power). Considering that Brillas and coworkers [30] showed that the role played by boron doping is not very significant, we infer that for BDD anodes with higher $\mathrm{sp}^{3} / \mathrm{sp}^{2} \mathrm{C}$ ratios $(\geq 215)$ 


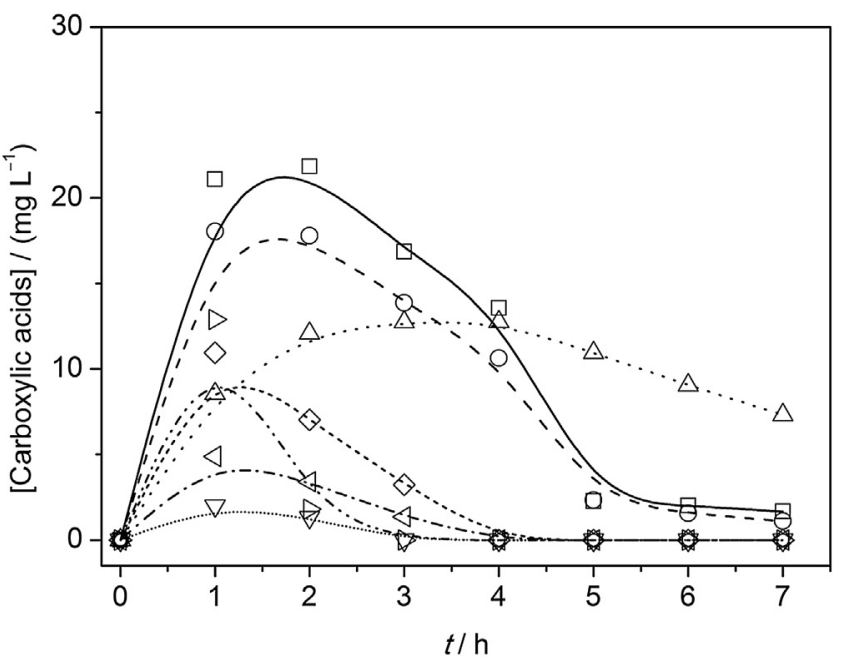

Fig. 7. Evolution of the concentration of the main detected carboxylic acids as a function of electrolysis time using a $\mathrm{BDD}_{500}$ anode: $(\nabla)$ butyric, $(\triangleright)$ glycolic, $(\triangleleft)$ glyoxylic, $(\square)$ oxalic, $(\triangle)$ oxamic, $(\diamond)$ propionic, and $(\bigcirc)$ tartronic acid. Electrolysis conditions: $10 \mathrm{mAcm}^{-2}$ at $40^{\circ} \mathrm{C}$, and no $\mathrm{pH}$ control.

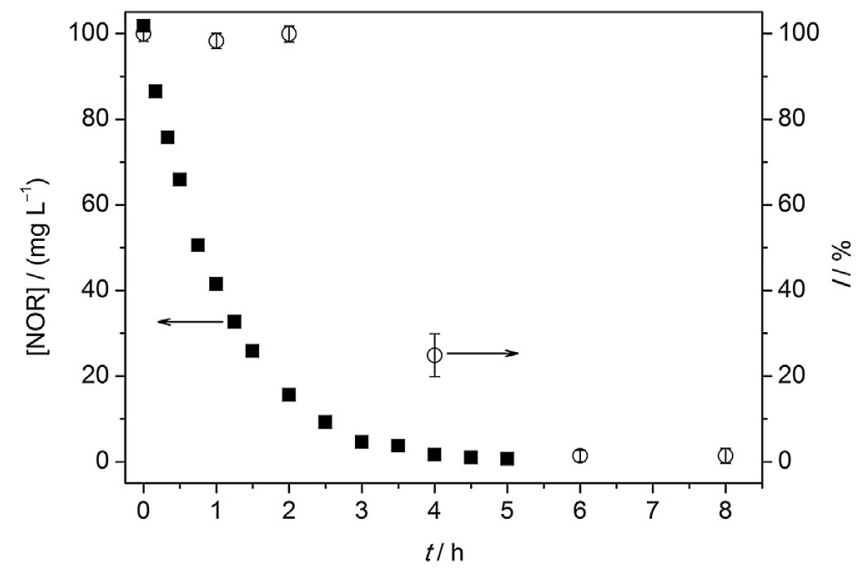

Fig. 8. Evolution of $[N O R]$ and the inhibition index $(I)$ as a function of the electrolysis time using a $\mathrm{BDD}_{500}$ anode: $(\boldsymbol{\square})[\mathrm{NOR}]$ and $(O) I$. The error bars refer to the calculated errors for triplicate analyses. Electrolysis conditions: $10 \mathrm{~mA} \mathrm{~cm}^{-2}$ at $40^{\circ} \mathrm{C}$, and no $\mathrm{pH}$ control.

the difference in their oxidation power is no longer significant; consequently, they yielded similar TOC removal performances in the electrooxidation of NOR. Furthermore, most probably due to the higher oxidation power of the BDD films (combined with the better transport conditions provided by the flow reactor), a better TOC removal performance was attained during NOR electrooxidation, compared to that for ENRO. In the case of LEVO electrooxidation using a $\mathrm{RuO}_{2} / \mathrm{Ti}$ anode, the TOC removal performance was poor ( $10 \%$ removal at most), which is understandable considering the low oxidation power of this type of anode (see [16]). Clearly, the data here reported for NOR constitute so far the best electrooxidation results for a fluoroquinolone, which can be attributed to the high oxidation power of the BDD anodes as well as to the electrochemical flow system used.

\section{Conclusions}

The electrochemical mineralization of NOR using a filter-press flow reactor was successfully attained with BDD anodes of distinct characteristics, independently of the solution $\mathrm{pH}$, and at low current densities, as the system is controlled by mass transport.
The experimental and theoretical curves (based on a purely mass transport controlled process) for the removal of NOR were slightly different, most probably due to the contribution of a chemical process mediated by electrogenerated oxidants. The mineralization rate, mineralization current efficiency, and energy consumption were very similar for all tested BDD anodes, under mass or charge transport limitation. Moreover, the detected intermediate compounds, aromatic or carboxylic acids, were the same for the tested BDD anodes. The small number of aromatic by-products formed and the high values of the extent of electrochemical combustion once again attest the high oxidation power of the BDD anode, which leads to a high $\mathrm{CO}_{2}$ conversion, i.e. hard oxidation, independently of the boron-doping level or $\mathrm{sp}^{3} / \mathrm{sp}^{2}$ carbon ratio. Finally, the toxicity of the electrolyzed solution to E. coli was completely removed only when the fluoroquinolone structure was broken by hydroxylation reactions taking place near the surface of the BDD anode, leading to a [NOR] value too low to inhibit the growth of the bacteria.

\section{Acknowledgments}

São Paulo Research Foundation (FAPESP - grant numbers: 2008/ 10449-7, 2012/13587-7, and 2014/11597-0) and CNPq (specially grant number 487270/2012-6) are gratefully acknowledged for financial support and scholarships. The company Vita Nova is also gratefully acknowledged for supplying NOR samples.

\section{Appendix A. Supplementary data}

Supplementary data associated with this article can be found, in the online version, at http://dx.doi.org/10.1016/j. electacta.2016.08.003.

\section{References}

[1] E.H. Oelkers, J.G. Hering, C. Zhu, Water Is there a global crisis? Elements 7 (2011) 157.

[2] N. Kemper, Veterinary antibiotics in the aquatic and terrestrial environment, Ecol. Indic. 8 (2008) 1.

[3] M.A.F. Locatelli, F.F. Sodré, W.F. Jardim, Determination of antibiotics in Brazilian surface waters using liquid chromatography-electrospray tandem mass spectrometry, Arch. Environ. Contam. Toxicol. 60 (2011) 385.

[4] I. Michael, L. Rizzo, C.S. McArdell, C.M. Manaia, C. Merlin, T. Schwartz, C. Dagot, D. Fatta-Kassinos, Urban wastewater treatment plants as hotspots for the release of antibiotics in the environment: A review, Water Res. 47 (2013) 957.

[5] Y. Luo, W. Guo, H.H. Ngo, L.D. Nghiem, F.I. Hai, J. Zhang, S. Liang, X.C. Wang, A review on the occurrence of micropollutants in the aquatic environment and their fate and removal during wastewater treatment, Sci. Total Environ. 473474 (2014) 619.

[6] D. Fatta-Kassinos, M.I. Vasquez, K. Kümmerer, Transformation products of pharmaceuticals in surface waters and wastewater formed during photolysis and advanced oxidation processes-Degradation, elucidation of byproducts and assessment of their biological potency, Chemosphere 85 (2011) 693.

[7] C. Gadipelly, A. Pe'rez-Gonza'lez, G.D. Yadav, I. Ortiz, R. Iba'nez, V.K. Rathod, K. V. Marathe, Pharmaceutical industry wastewater: review of the technologies for water treatment and reuse, Ind. Eng. Chem. Res. 53 (2014) 11571.

[8] V. Homem, L. Santos, Degradation and removal methods of antibiotics from aqueous matrices-A review, J. Environ. Manage. 92 (2011) 2304.

[9] M. Panizza, G. Cerisola, Direct and mediated anodic oxidation of organic pollutants, Chem. Rev. 109 (2009) 6541.

[10] X. Yu, M. Zhou, Y. Hu, K.G. Serrano, F. Yu, Recent updates on electrochemical degradation of bio-refractory organic pollutants using BDD anode: a mini review, Environ. Sci Pollut. Res. 21 (2014) 8417

[11] E. Brillas, C.A. Martínez-Huitle, Decontamination of wastewaters containing synthetic organic dyes by electrochemical methods. An updated review, Appl. Catal. B 166-167 (2015) 603.

[12] A. Fernandes, M.J. Pacheco, L. Ciríaco, A. Lopes, Review on the electrochemical processes for the treatment of sanitary landfill leachates: Present and future, Appl. Catal. B 176-177 (2015) 183.

[13] C.A. Martínez-Huitle, M.A. Rodrigo, I. Sire's, O. Scialdone, Single and coupled electrochemical processes and reactors for the abatement of organic water pollutants: A critical review, Chem. Rev 115 (2015) 13362.

[14] J. Radjenovic, D.L. Sedlak, Challenges and opportunities for electrochemical processes as next-generation technologies for the treatment of contaminated water, Environ. Sci. Technol 49 (2015) 11292 
[15] H. Särkkä, A. Bhatnagar, M. Sillanpää, Recent developments of electrooxidation in water treatment-A review, J. Electroanal. Chem. 754 (2015) 46.

[16] A. Kapalka, G. Fóti, C. Comninellis, Kinetic modelling of the electrochemical mineralization of organic pollutants for wastewater treatment, J. Appl. Electrochem. 38 (2008) 7.

[17] A. Urtiaga, P. Fernandez-Castro, P. Gomez, I. Ortiz, Remediation of wastewaters containing tetrahydrofuran. Study of the electrochemical mineralization on BDD electrodes, Chem. Eng. J. 239 (2014) 341.

[18] G.F. Pereira, R.C. Rocha-Filho, N. Bocchi, S.R. Biaggio, Electrochemical degradation of the herbicide picloram using a filter-press flow reactor with a boron-doped diamond or $\beta-\mathrm{PbO}_{2}$ anode, Electrochim. Acta 179 (2015) 588.

[19] F.L. Souza, C. Sáez, M.R.V. Lanza, P. Cañizares, M.A. Rodrigo, The effect of the $\mathrm{sp}^{3} / \mathrm{sp}^{2}$ carbon ratio on the electrochemical oxidation of $24-\mathrm{D}$ with $\mathrm{p}-\mathrm{Si}$ BDD anodes, Electrochim. Acta 187 (2016) 119.

[20] R.F. Brocenschi, R.C. Rocha-Filho, N. Bocchi, S.R. Biaggio, Electrochemical degradation of estrone using a boron-doped diamond anode in a filter-press reactor, Electrochim. Acta 197 (2016) 186.

[21] E. Guinea, J.A. Garrido, R.M. Rodríguez, P.-L. Cabot, C. Arias, F. Centellas, E. Brillas, Degradation of the fluoroquinolone enrofloxacin by electrochemical advanced oxidation processes based on hydrogen peroxide electrogeneration, Electrochim. Acta 55 (2010) 2101.

[22] V.S. Antonin, M.C. Santos, S. Garcia-Segura, E. Brillas, Electrochemical incineration of the antibiotic ciprofloxacin in sulfate medium and synthetic urine matrix, Water Res. 83 (2015) 31.

[23] A. El-Ghenymy, F. Centellas, R.M. Rodríguez, P.L. Cabot, J.A. Garrido, I. Sirés, E. Brillas, Comparative use of anodic oxidation, electro-Fenton and photoelectroFenton with Pt or boron-doped diamond anode to decolorize and mineralize Malachite Green oxalate dye, Electrochim. Acta 182 (2015) 247.

[24] F.L. Souza, C. Saéz, M.R.V. Lanza, P. Cañizares, M.A. Rodrigo, Removal of herbicide 2,4-D using conductive-diamond sonoelectrochemical oxidation, Sep. Purif. Technol. 149 (2015) 24.

[25] K. Pecková, J. Musilová, J. Barek, Boron-doped diamond film electrodes-New tool for voltammetric determination of organic substances, Crit. Rev. Anal. Chem. 39 (2009) 148.

[26] T.A. Silva, G.F. Pereira, O. Fatibello-Filho, K.I.B. Eguiluz, G.R. Salazar-Banda, Square-wave voltammetric determination of rosuvastatin calcium in pharmaceutical and biological fluid samples using a cathodically pretreated boron-doped diamond electrode, Diamond Relat. Mater. 58 (2015) 103.

[27] I. Sanjuan, A. Brotons, N. Hernandez-Ibanez, C.W. Foster, C.E. Banks, J. Iniesta, Boron-doped diamond electrodes explored for the electroanalytical detection of 7-methylguanine and applied for its sensing within urine samples, Electrochim. Acta 197 (2016) 167.

[28] M. Panizza, G. Cerisola, Application of diamond electrodes to electrochemical processes, Electrochim. Acta 51 (2005) 191.

[29] A. Kapalka, G. Fóti, C. Comninellis, The importance of electrode material in environmental electrochemistry: Formation and reactivity of free hydroxyl radicals on boron-doped diamond electrodes, Electrochim. Acta 54 (2009) 2018.

[30] E. Guinea, F. Centellas, E. Brillas, P. Cañizares, C. Sáez, M.A. Rodrigo, Electrocatalytic properties of diamond in the oxidation of a persistant pollutant, Appl. Catal. B 89 (2009) 645.

[31] D.M. de Araújo, P. Cañizares, C.A. Martínez-Huitle, M.A. Rodrigo, Electrochemical conversion/combustion of a model organic pollutant on BDD anode: Role of $\mathrm{sp}^{3} / \mathrm{sp}^{2}$ ratio, Electrochem. Commun. 47 (2014) 37.

[32] E. Guinea, E. Brillas, F. Centellas, P. Cañizares, M.A. Rodrigo, C. Sáez, Oxidation of enrofloxacin with conductive-diamond electrochemical oxidation, ozonation and Fenton oxidation. A comparison, Water Res. 43 (2009) 2131.

[33] J.M. Aquino, R.C. Rocha-Filho, C. Sáez, P. Cañizares, M.A. Rodrigo, High efficiencies in the electrochemical oxidation of an anthraquinonic dye with conductive-diamond anodes, Environ. Sci. Pollut. Res 21 (2014) 8442.

[34] J.M. Aquino, R.C. Rocha-Filho, N. Bocchi, S.R. Biaggio, Electrochemical degradation of the Reactive Red 141 dye on a $\beta-\mathrm{PbO}_{2}$ anode assessed by the response surface methodology, J. Braz. Chem. Soc. 21 (2010) 324.
[35] H. Li, X. Zhu, J. Ni, Inactivation of Escherichia coli in $\mathrm{Na}_{2} \mathrm{SO}_{4}$ electrolyte using boron-doped diamond anode, Electrochim. Acta 56 (2010) 448.

[36] S. Silambarasan, A.S. Vangnai, Biodegradation of 4-nitroaniline by plantgrowth promoting Acinetobacter sp. AVLB2 and toxicological analysis of its biodegradation metabolites, J. Hazard. Mater. 302 (2016) 426.

[37] E. Brillas, I. Sirés, M.A. Oturan, Electro-Fenton process and related electrochemical technologies based on Fenton's reaction chemistry, Chem. Rev. 109 (2009) 6570.

[38] D.W. Miwa, G.R.P. Malpass, S.A.S. Machado, A.J. Motheo, Electrochemical degradation of carbaryl on oxide electrodes, Water Res. 40 (2006) 3281.

[39] A. Medel, E. Bustos, L.M. Apátiga, Y. Meas, Surface activation of C-sp ${ }^{3}$ in borondoped diamond electrode, Electrocatalysis 4 (2013) 189.

[40] D.A.C. Coledam, J.M. Aquino, R.C. Rocha-Filho, N. Bocchi, S.R. Biaggio, Influence of chloride-mediated oxidation on the electrochemical degradation of the Direct Black 22 dye using boron-doped diamond and $\beta-\mathrm{PbO}_{2}$ anodes, Quim. Nova 37 (2014) 1312.

[41] M. Panizza, G. Cerisola, Electrochemical degradation of Methyl Red using BDD and $\mathrm{PbO}_{2}$ anodes, Ind. Eng. Chem. Res. 47 (2008) 6816.

[42] P. Cañizares, J. García-Gómez, I.F. de-Marcos, M.A. Rodrigo, J. Lobato, Measurement of mass-transfer coefficients by an electrochemical technique, J. Chem. Educ. 83 (2006) 1204.

[43] A.D. Eaton, L.S. Clesceri, A.E. Greenberg, Standard Methods for the Examination of Water and Wastewater, 19th ed., United Book Press, Baltimore, 1995.

[44] S. Fierro, K. Abe, C. Comninellis, Y. Einaga, Influence of doping level on the electrochemical oxidation of formic acid on boron doped diamond electrodes, J. Electrochem. Soc. 158 (2011) F183.

[45] F. Souza, C. Sáez, M.R.V. Lanza, P. Cañizares, M.A. Rodrigo, The effect of the $\mathrm{sp}^{3} /$ $\mathrm{sp}^{2}$ carbon ratio on the electrochemical oxidation of $24-\mathrm{D}$ with $\mathrm{p}-\mathrm{Si} \mathrm{BDD}$ anodes, Electrochim. Acta 187 (2016) 119.

[46] F. Souza, C. Sáez, P. Cañizares, A.J. Motheo, M.A. Rodrigo, Electrochemical removal of dimethyl phthalate with diamond anodes, J. Chem. Technol. Biotechnol 89 (2014) 282.

[47] F.L. Souza, J.M. Aquino, K. Irikura, D.W. Miwa, M.A. Rodrigo, A.J. Motheo, Electrochemical degradation of the dimethyl phthalate ester on a fluoridedoped Ti/ß-PbO 2 anode, Chemosphere 109 (2014) 187.

[48] P. Cañizares, J. García-Gómez, J. Lobato, M.A. Rodrigo, Modeling of wastewater electro-oxidation processes part I. General description and application to inactive electrodes, Ind. Eng. Chem. Res. 43 (2004) 1915.

[49] D.-W. Kim, T.M. Heinze, B.-S. Kim, L.K. Schnackenberg, K.A. Woodling, J.B. Sutherland, Modification of norfloxacin by a Microbacterium sp. strain isolated from a wastewater treatment plant, Appl. Environ. Microbiol. 77 (2011) 6100

[50] T. An, H. Yang, W. Song, G. Li, H. Luo, W.J. Cooper, Mechanistic considerations for the advanced oxidation treatment of fluoroquinolone pharmaceutical compounds using $\mathrm{TiO}_{2}$ heterogeneous catalysis, J. Phys. Chem. A 114 (2010) 2569.

[51] U. Hubicka, P. Zmudzki, B. Zuromska-Witek, P. Zajdel, M. Pawlowski, J. Krzek, Separation and characterization of ciprofloxacin, difloxacin, lomefloxacin, norfloxacin, and ofloxacin oxidation products under potassium permanganate treatment in acidic medium by UPLC-MS/MS, Talanta 109 (2013) 91.

[52] C. Liu, V. Nanaboina, G.V. Korshin, W. Jiang, Spectroscopic study of degradation products of ciprofloxacin, norfloxacin and lomefloxacin formed in ozonated wastewater, Water Res. 46 (2012) 5235.

[53] I. Ahmad, R. Bano, S.G. Musharraf, M.A. Sheraz, S. Ahmed, H. Tahir, Q.U. Arfeen, M.S. Bhatti, Z. Shad, S.F. Hussain, Photodegradation of norfloxacin in aqueous and organic solvents: A kinetic study, J. Photochem. Photobiol. A 302 (2015) 1.

[54] S. Garcia-Segura, E. Brillas, Mineralization of the recalcitrant oxalic and oxamic acids by electrochemical advanced oxidation processes using a boron-doped diamond anode, Water Res. 45 (2011) 2975.

[55] S.R. Norrby, M. Jonsson, Antibacterial activity of norfloxacin, Antimicrob. Agents Chemother. 23 (1983) 15.

[56] Y. Gong, J. Li, Y. Zhang, M. Zhang, X. Tian, A. Wang, Partial degradation of levofloxacin for biodegradability improvement by electro-Fenton process using an activated carbon fiber felt cathode, J. Hazard. Mater. 304 (2016) 320. 